\title{
Impact of changes in body mass index after percutaneous coronary intervention on long-term outcomes in patients with coronary artery disease
}

\author{
Hisanori Yui ${ }^{1}$ - Soichiro Ebisawa ${ }^{1} \cdot$ Takashi Miura $^{2}$. Chie Nakamura ${ }^{1}$ - Shusaku Maruyama ${ }^{1}$. Daisuke Kashiwagi ${ }^{1}$. \\ Ayumu Nagae ${ }^{1} \cdot$ Takahiro Sakai $^{1} \cdot$ Tamon Kato $^{1} \cdot$ Tatsuya Saigusa $^{1}$ - Ayako Okada ${ }^{1} \cdot$ Hirohiko Motoki $^{1}$. \\ Koichiro Kuwahara ${ }^{1}$
}

Received: 2 March 2020 / Accepted: 17 June 2020 / Published online: 25 June 2020

(c) The Author(s) 2020

\begin{abstract}
Little is known about the impact of changes in body mass index (BMI) after the percutaneous coronary intervention (PCI) on long-term outcomes in patients with coronary artery disease (CAD). Therefore, this study aimed to clarify this issue. We investigated data on CAD obtained from the SHINANO Registry, a prospective, observational, multicenter cohort study, from 2012 to 2013 in Nagano, Japan. One year after PCI, the enrolled patients were divided into the following three groups based on changes in BMI by tertiles: reduced, maintained, and elevated BMI. The associations among the groups and the 4-year outcomes [major adverse cardiac events (MACEs), all-cause death, Q-wave myocardial infarction, and stroke] were examined. Five hundred seventy-two patients were divided into the reduced, maintained, and elevated BMI groups. Over the 4-year follow-up period, the cumulative incidence of MACEs was 10.5\% (60 cases). In the Kaplan-Meier analysis, the incidence rates of MACE were significantly higher in the reduced BMI group than in the maintained and elevated BMI groups [17.7\% versus (vs.) $7.3 \%$ vs. 9.0\%, $p=0.004]$. Multivariable cox regression analysis showed that the reduced group showed increased risks of MACEs (hazard ratio 2.15; 95\% confidence interval 1.29-3.57; $p=0.003$ ). The long-term clinical outcomes of patients with CAD who underwent PCI were affected by the reduction in BMI after PCI. Furthermore, the elevation of BMI after PCI was not a poor prognostic factor.
\end{abstract}

Keywords Obesity paradox $\cdot$ Percutaneous coronary intervention $\cdot$ Coronary artery disease $\cdot$ Prognosis

\section{Introduction}

Obesity is a poor prognostic factor in the general population [1], and being lean is an important determinant of premature death [2]. Obesity is generally assessed by body mass index (BMI), and individuals with obesity (BMI of $30.0 \mathrm{~kg} / \mathrm{m}^{2}$ ) have a high incidence of coronary artery disease (CAD) [3]. A previous report demonstrated that obesity is an independent risk factor for developing heart failure [4]. However,

Hisanori Yui

hyui@shinshu-u.ac.jp

1 Department of Cardiovascular Medicine, Shinshu University School of Medicine, 3-1-1 Asahi, Matsumoto-shi, Nagano 390-8621, Japan

2 Department of Cardiology, Nagano Municipal Hospital, Nagano, Japan weight loss has been reported to be an independent prognostic factor in patients who have already developed heart failure [5-7], and this is the "obesity paradox".

Little is known about the impact of changes in BMI after PCI on long-term outcomes in patients with CAD. Weight changes after PCI can be used to provide patients with careful care, follow-up, and prognostic explanations if the existence of the obesity paradox in CAD is clarified. Therefore, this study aimed to clarify the impact of changes in BMI after PCI on long-term outcomes in patients with CAD.

\section{Methods}

The SHINANO Registry was developed in accordance with the Declaration of Helsinki and was approved by the ethics committee of each participating hospital. Patients who gave written informed consent were enrolled. 
The SHINANO Registry was a prospective, multicenter, observational, cohort registry of patients with any type of CAD, including stable angina, ST-segment elevation myocardial infarction (STEMI), non-STEMI, and unstable angina (UA), who underwent PCI in one of 14 hospitals in the Nagano prefecture of Japan between August 2012 and July 2013. This study was registered with the University Hospital Medical Information Network Clinical Trials Registry, as accepted by the International Committee of Medical Journal Editors (UMIN-ID: 000010070). This study had no exclusion criteria and was an all-comers registry.

The 1992 patients were registered in the SHINANO registry. We excluded 1420 patients with missing BMI $(n=1160)$, an event within 1 year after PCI $(n=131$; because of the possibility that the condition was getting worse), and histories of heart failure and dialysis $(n=83$ and 46 ; because of the possibility that the conditions affected weight). The time of initiating the follow-up period was from the point of 1 year after PCI. Patients were prospectively followed for 4 years. The final sample of 572 patients was divided into three groups based on the original amount of BMI change for 1 year in tertiles: reduced BMI group $\left(<-0.52 \mathrm{~kg} / \mathrm{m}^{2}\right.$; $n=191)$, maintained BMI group $\left(-0.52\right.$ to $0.38 \mathrm{~kg} / \mathrm{m}^{2}$; $n=191)$, and elevated BMI group $\left(\geq 0.38 \mathrm{~kg} / \mathrm{m}^{2} ; n=190\right)$ (Fig. 1).

The primary outcome was major adverse cardiovascular events (MACE), namely all-cause death, myocardial infarction (MI), and stroke at 4 years. The secondary outcomes were cardiac death, bleeding event, and target lesion revascularization. Cardiac death was defined as any of sudden death, death with no apparent cause other than heart disease, or death due to heart failure or myocardial infarction.
Bodyweight was measured to the nearest $0.1 \mathrm{~kg}$ using a digital scale, and height was measured to the nearest $0.1 \mathrm{~cm}$; the patient stood without shoes. BMI was calculated by dividing weight $(\mathrm{kg})$ by height squared $\left(\mathrm{m}^{2}\right)$. Acute coronary syndrome (ACS) patients weighed on a weighable bed after PCI. ACS was a composite of STEMI, NSTEMI, and UA. ACS positive meant that the first PCI was performed on patients with ACS during the enrollment period. STEMI was diagnosed based on a chest symptom; ST elevation of $1 \mathrm{mV}$ in two or more limb leads, or two contiguous precordial leads, or left bundle branch block; and elevation of biochemical markers of myocardial necrosis (troponin $T$ value of $0.01 \mathrm{ng} / \mathrm{mL}$ or creatine phosphokinase level more than twice the normal range). NSTEMI was diagnosed based on a chest symptom, ST depression of $0.05 \mathrm{mV}, T$ wave inversion of $>0.3 \mathrm{mV}$ or transient ST-segment elevation of $0.05 \mathrm{mV}$, and elevated biochemical markers of myocardial necrosis. UA was diagnosed based on persistent resting or nocturnal chest pain with additional findings. Angiographic success was defined as the achievement of a reduction in the minimum stenosis diameter to $20 \%$ with grade 3 Thrombolysis in Myocardial Infarction flow. Diabetes was defined as a glycated hemoglobin level of $\geq 6.5 \%$, fasting plasma glucose level of $\geq 126 \mathrm{mg} / \mathrm{dL}$, or treatment with hypoglycemic agents. Hypertension was defined as a systolic blood pressure of $\geq 140 \mathrm{mmHg}$, diastolic blood pressure of $\geq 90 \mathrm{mmHg}$, or ongoing treatment for hypertension. Dyslipidemia was defined as a serum total cholesterol level of $\geq 220 \mathrm{mg} / \mathrm{dL}$, a low-density lipoprotein cholesterol level of $\geq 140 \mathrm{mg} / \mathrm{dL}$ or higher, or receipt of current lipid-lowering therapy. Left ventricular ejection fraction (LVEF) was determined using the Teichholz method, and LVEF of $\leq 40 \%$ indicated left ventricular systolic dysfunction. Low BMI
Fig. 1 Study flow diagram illustrating the inclusion process and exclusion criteria. $B M I$ body mass index, $P C I$ percutaneous coronary intervention

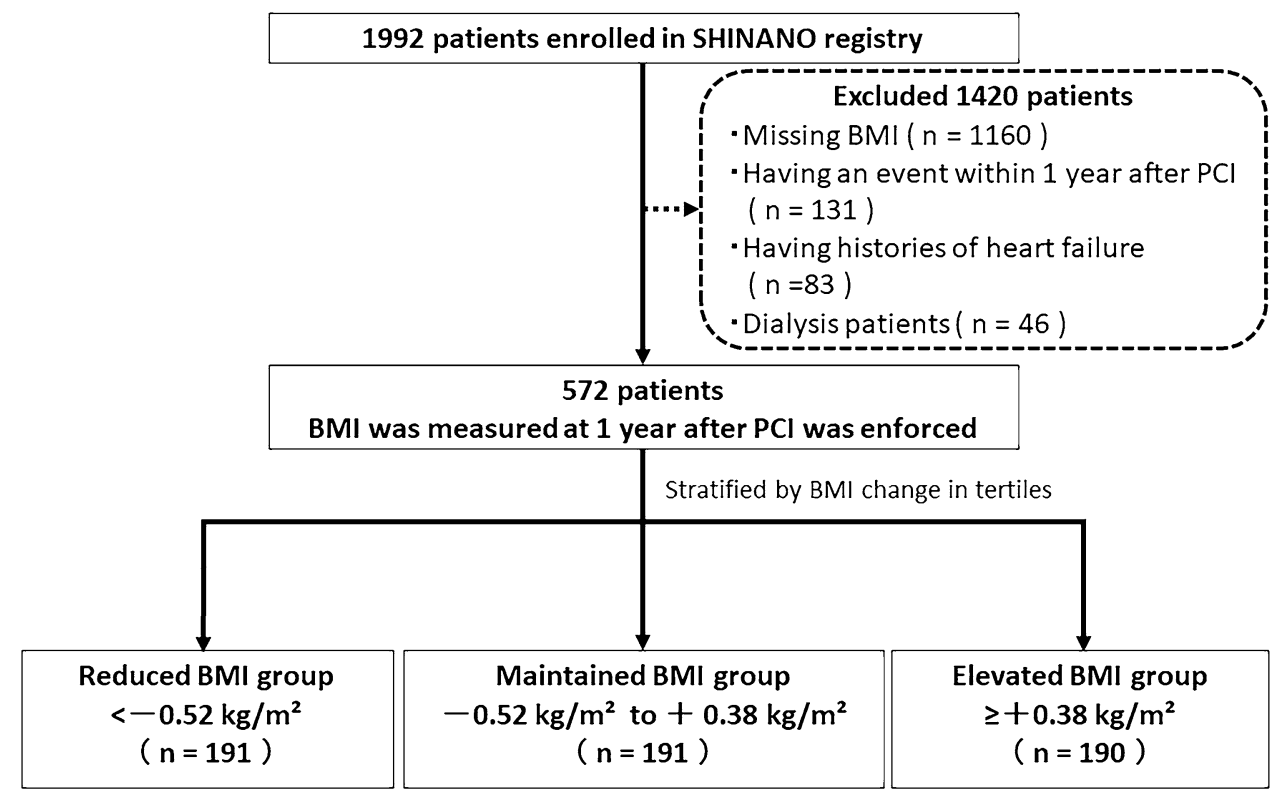


and high BMI were defined as BMI of $<18.5 \mathrm{~kg} / \mathrm{m}^{2}$ and of $>30 \mathrm{~kg} / \mathrm{m}^{2}$. A bleeding event was defined as a bleed that required treatment.

Normality was assessed according to results from a Shapiro-Wilk test. Continuous variables were reported as mean \pm standard deviation if normally distributed as median and interquartile range otherwise. Categorical variables were reported as numbers and percentages. Group differences were analyzed using the $\chi^{2}$ test for categorical variables and the Kruskal-Wallis test for continuous variables. The Kaplan-Meier test was used to assess the cumulative incidence of MACE. The log-rank test was used to estimate group differences. Multivariable Cox regression analysis was used to identify the independent predictors of MACE; variables clinically associated with MACE were entered into the multivariable model. Analyses were performed using
Statistical Package for Social Science version 25 (SPSS Inc., Chicago, Illinois, USA).

\section{Results}

Baseline characteristics are shown in Table 1 . The average patient age was 70.2 years, $77.2 \%$ were men, and the average BMI was $23.9 \mathrm{~kg} / \mathrm{m}^{2}$ (range $14.1-38.8 \mathrm{~kg} / \mathrm{m}^{2}$ ). Of the traditional coronary risk factors, $75.2 \%$ of patients had hypertension, $61.7 \%$ had dyslipidemia, $35.8 \%$ had diabetes mellitus, and $56.2 \%$ had a history of smoking. There was no significant difference in the background of the 3 groups. 1 year after PCI, the mean BMI was also in the normal range in each group: reduced BMI group $\left(22.6 \pm 3.7 \mathrm{~kg} / \mathrm{m}^{2}\right)$, maintained BMI group $\left(23.8 \pm 3.4 \mathrm{~kg} / \mathrm{m}^{2}\right)$, and elevated BMI

Table 1 Baseline patient characteristics

\begin{tabular}{|c|c|c|c|c|c|}
\hline & $\begin{array}{l}\text { Overall } \\
N=572\end{array}$ & $\begin{array}{l}\text { Reduced BMI } \\
N=191\end{array}$ & $\begin{array}{l}\text { Maintained BMI } \\
N=191\end{array}$ & $\begin{array}{l}\text { Elevated BMI } \\
N=190\end{array}$ & $p$ value \\
\hline Age, years & $71.0(64.0,77.0)$ & $72.5(64.0,79.0)$ & $70.0(64.0,77.0)$ & $71.0(64.0,75.5)$ & 0.36 \\
\hline Sex, no. of men $(\%)$ & $442(77.2 \%)$ & $152(79.6 \%)$ & $148(77.5 \%)$ & $142(74.7 \%)$ & 0.53 \\
\hline BMI $\left(\mathrm{kg} / \mathrm{m}^{2}\right)$ & $23.6(21.9,25.8)$ & $24.1(22.0,26.5)$ & $23.7(22.0,25.9)$ & $23.3(21.4,25.1)$ & 0.08 \\
\hline High BMI, $n(\%)$ & $27(4.7 \%)$ & $12(6.3 \%)$ & $8(4.2 \%)$ & $7(3.7 \%)$ & 0.45 \\
\hline Low BMI, $n(\%)$ & $27(4.7 \%)$ & $6(3.1 \%)$ & $9(4.7 \%)$ & $12(6.3 \%)$ & 0.34 \\
\hline Hypertension, $n(\%)$ & $430(75.2 \%)$ & $147(77.0 \%)$ & $148(77.5 \%)$ & $135(71.1 \%)$ & 0.27 \\
\hline Dyslipidemia, $n(\%)$ & $353(61.7 \%)$ & $118(61.8 \%)$ & $128(67.0 \%)$ & $107(56.3 \%)$ & 0.10 \\
\hline Diabetes mellitus, $n(\%)$ & $205(35.8 \%)$ & $73(38.4 \%)$ & $74(38.7 \%)$ & $58(30.5 \%)$ & 0.17 \\
\hline Smoking, $n(\%)$ & $322(56.2 \%)$ & $110(57.6 \%)$ & $108(57.1 \%)$ & $104(55.6 \%)$ & 0.92 \\
\hline LDL cholesterol level (mg/dL) & $103.0(84.0,127.0)$ & $104.5(87.0,122.0)$ & $102.0(81.0,128.3)$ & $106.0(83.0,129.0)$ & 0.81 \\
\hline HDL cholesterol level (mg/dL) & $47.0(40.0,56.0)$ & $45.0(39.0,56.0)$ & $47.0(40.0,55.0)$ & $47.0(41.0,57.0)$ & 0.46 \\
\hline TG level (mg/dL) & $115.0(82.5,172.5)$ & $114.5(74.0,180.0)$ & $113.0(83.8,165.5)$ & $118.0(85.5,174.0)$ & 0.33 \\
\hline HbA1c level (\%) & $5.9(5.6,6.5)$ & $6.0(5.6,6.6)$ & $6.0(5.6,6.5)$ & $5.9(5.5,6.3)$ & 0.49 \\
\hline eGFR, $\left(\mathrm{mL} / \mathrm{min} / 1.73 \mathrm{~m}^{2}\right)$ & $65.2(54.9,78.8)$ & $65.5(54.3,74.4)$ & $67.3(57.8,81.3)$ & $62.5(51.0,79.5)$ & 0.20 \\
\hline $\mathrm{LVD}, n(\%)$ & $22(11.7 \%)$ & $22(11.7 \%)$ & $17(9.0 \%)$ & $16(8.8 \%)$ & 0.57 \\
\hline $\mathrm{EF}(\%)$ & $64.0(55.0,68.5)$ & $65.0(56.0,68.0)$ & $64.0(54.9,69.0)$ & $62.7(53.0,68.0)$ & 0.49 \\
\hline Af, $n(\%)$ & $51(8.9 \%)$ & $15(7.9 \%)$ & $19(9.9 \%)$ & $17(8.9 \%)$ & 0.77 \\
\hline Aspirin use, $n(\%)$ & $556(97.2 \%)$ & $187(98.4 \%)$ & $185(97.9 \%)$ & $184(97.9 \%)$ & 0.91 \\
\hline Thienopiridines use, $n(\%)$ & $520(90.9 \%)$ & $171(90.0 \%)$ & $174(92.1 \%)$ & $175(93.1 \%)$ & 0.54 \\
\hline Warfarin use, $n(\%)$ & $57(10.0 \%)$ & $16(8.4 \%)$ & $17(9.0 \%)$ & $24(12.8 \%)$ & 0.31 \\
\hline Statins use, $n(\%)$ & $479(83.7 \%)$ & $159(83.7 \%)$ & $156(83.0 \%)$ & $164(87.2 \%)$ & 0.47 \\
\hline ACEi use, $n(\%)$ & $201(35.1 \%)$ & $67(35.3 \%)$ & $66(34.9 \%)$ & $68(36.4 \%)$ & 0.95 \\
\hline ARB use, $n(\%)$ & $209(36.5 \%)$ & $66(34.7 \%)$ & $73(38.8 \%)$ & $70(37.4 \%)$ & 0.70 \\
\hline B-blocker use, $n(\%)$ & $241(42.1 \%)$ & $71(37.4 \%)$ & $83(44.4 \%)$ & $87(46.5 \%)$ & 0.17 \\
\hline No. of diseased vessels & $1.0(1.0,2.0)$ & $1.0(1.0,2.0)$ & $1.0(1.0,2.0)$ & $1.0(1.0,2.0)$ & 0.80 \\
\hline SYNTAX score & $11.0(6.3,18.3)$ & $12.0(6.8,18.0)$ & $11.0(6.8,19.1)$ & $10.5(6.0,19.0)$ & 0.85 \\
\hline $\mathrm{ACS}, n(\%)$ & $259(45.3 \%)$ & $91(47.6 \%)$ & $75(39.3 \%)$ & $93(48.9 \%)$ & 0.12 \\
\hline
\end{tabular}

Data are shown as median and interquartile range otherwise or $n(\%)$

$A C E-I$ angiotensin-converting enzyme inhibitor, $A C S$ acute coronary syndrome, $A f$ atrial fibrillation, $A R B$ angiotensin receptor blocker, $B M I$ body mass index, $E F$ ejection fraction, $e G F R$ estimated glomerular filtration rate, $H b A 1 C$ glycated hemoglobin, $H D L$ high-density lipoprotein cholesterol, High BMI high body mass index $\left(>30 \mathrm{~kg} / \mathrm{m}^{2}\right), L D L-C$ low-density lipoprotein cholesterol, Low BMI low body mass index $\left(<18.5 \mathrm{~kg} / \mathrm{m}^{2}\right), L V D$ left ventricular dysfunction (ejection fraction $\left.<40 \%\right), T G$ triglyceride, no. number 
group $\left(24.8 \pm 3.6 \mathrm{~kg} / \mathrm{m}^{2}\right)$. During the follow-up period, 60 cases $(10.5 \%)$ of MACEs occurred, including 43 all-cause deaths, 4 non-fatal MIs, and 17 strokes (Table 2).

Figure 2 illustrates the cumulative incidence of MACEs according to each BMI group. The reduced BMI group had a significantly higher incidence of MACEs than the other groups ( $\chi^{2}$ test for linear trend, $p=0.004$, respectively). Figure 3 demonstrates the difference in each clinical event, according to change in the BMI tertile. The incidences of all-cause death were significantly higher in patients in the reduced BMI group than in the other groups $\left(\chi^{2}\right.$ for linear trend, $p=0.015$, respectively). This trend was the same for the incidence of cardiac death $\left(\chi^{2}\right.$ for linear trend, $p=0.030$, respectively). Only the reduced BMI group had a Q-wave myocardial infarction. There were no significant differences between the groups in the incidences of stroke $\left(\chi^{2}\right.$ for linear trend, $p=0.908$, respectively). Multivariable Cox regression analysis was performed to identify specific predictors of MACEs in the study population. After adjusting for age, sex, estimated glomerular filtration rate, LV systolic dysfunction, high and low BMI (at the time of registration), and history of hypertension, dyslipidemia, diabetes mellitus, atrial fibrillation, and ACS, reduced BMI showed a strong association with MACEs (hazard ratio 2.24; $95 \%$ confidence interval 1.34-3.75; $p=0.003$ ) (Table 3).

\section{Discussion}

In this study, we demonstrated that BMI change within 1 year after undergoing PCI could predict MACEs in patients with CAD. In particular, patients with reduced BMI $\left(\geq 0.52 \mathrm{~kg} / \mathrm{m}^{2}\right)$ had a higher incidence of MACEs than those with a maintained BMI $\left(-0.52\right.$ to $\left.0.38 \mathrm{~kg} / \mathrm{m}^{2}\right)$ and elevated BMI $\left(\geq 0.38 \mathrm{~kg} / \mathrm{m}^{2}\right)$ in this study.

Obesity is an independent risk factor for cardiovascular disease, including CAD and heart failure, and is associated with morbidity [4, 8-10]. It has been demonstrated that the relationship between BMI and mortality in elderly patients is represented by a large flat-bottomed U-shaped curve [11]. Additionally, low BMI is independently associated with an increased risk of 1-year mortality after PCI [12]. However, this study showed that weight loss after PCI treatment has impact on prognosis regardless of the weight before PCI

Table 2 4-year outcomes during the follow-up period

\begin{tabular}{|c|c|c|c|c|c|}
\hline & $\begin{array}{l}\text { Overall } \\
N=572\end{array}$ & $\begin{array}{l}\text { Reduced BMI } \\
N=191\end{array}$ & $\begin{array}{l}\text { Maintained BMI } \\
N=191\end{array}$ & $\begin{array}{l}\text { Elevated BMI } \\
N=190\end{array}$ & $p$ value \\
\hline MACEs, $n(\%)$ & $60(10.5 \%)$ & $31(16.2 \%)$ & $13(6.8 \%)$ & $16(8.4 \%)$ & $<0.01$ \\
\hline All-cause death, $n(\%)$ & $43(7.5 \%)$ & $23(12.0 \%)$ & $9(4.7 \%)$ & $11(5.8 \%)$ & 0.01 \\
\hline Q-wave myocardial infarction, $n(\%)$ & $4(0.7 \%)$ & $4(2.1 \%)$ & $0(0.0 \%)$ & $0(0.0 \%)$ & 0.02 \\
\hline Stroke, $n(\%)$ & $17(3.0 \%)$ & $6(3.1 \%)$ & $5(2.6 \%)$ & $6(3.2 \%)$ & 0.94 \\
\hline Cardiac death, $n(\%)$ & $38(6.6 \%)$ & $20(10.5 \%)$ & $8(4.2 \%)$ & $10(5.3 \%)$ & 0.03 \\
\hline Bleeding event, $n(\%)$ & $23(4.0 \%)$ & $12(6.3 \%)$ & $6(3.1 \%)$ & $5(2.6 \%)$ & 0.15 \\
\hline Target lesion revascularization, $n(\%)$ & $31(5.4 \%)$ & $13(6.8 \%)$ & $12(6.3 \%)$ & $6(3.2 \%)$ & 0.24 \\
\hline
\end{tabular}

$B M I$ body mass index, $M A C E$ major adverse cardiac or cerebrovascular events

Fig. 2 Kaplan-Meier analysis for the incidence of MACEs. Incidence of MACEs. The Kaplan-Meier curve for the cumulative incidence of MACEs is shown. MACEs include all-cause mortality, myocardial infarction, and stroke. The reduced BMI group $\left(<-0.52 \mathrm{~kg} / \mathrm{m}^{2} ; n=191\right)$ has a significantly higher incidence of MACEs than the maintained BMI group (-0.52 to $0.38 \mathrm{~kg}$ / $\left.\mathrm{m}^{2} ; n=191\right)$ and elevated BMI group ( $\left.\geq+0.38 \mathrm{~kg} / \mathrm{m}^{2} ; n=190\right)$. $B M I$ body mass index, MACE major adverse cardiac events

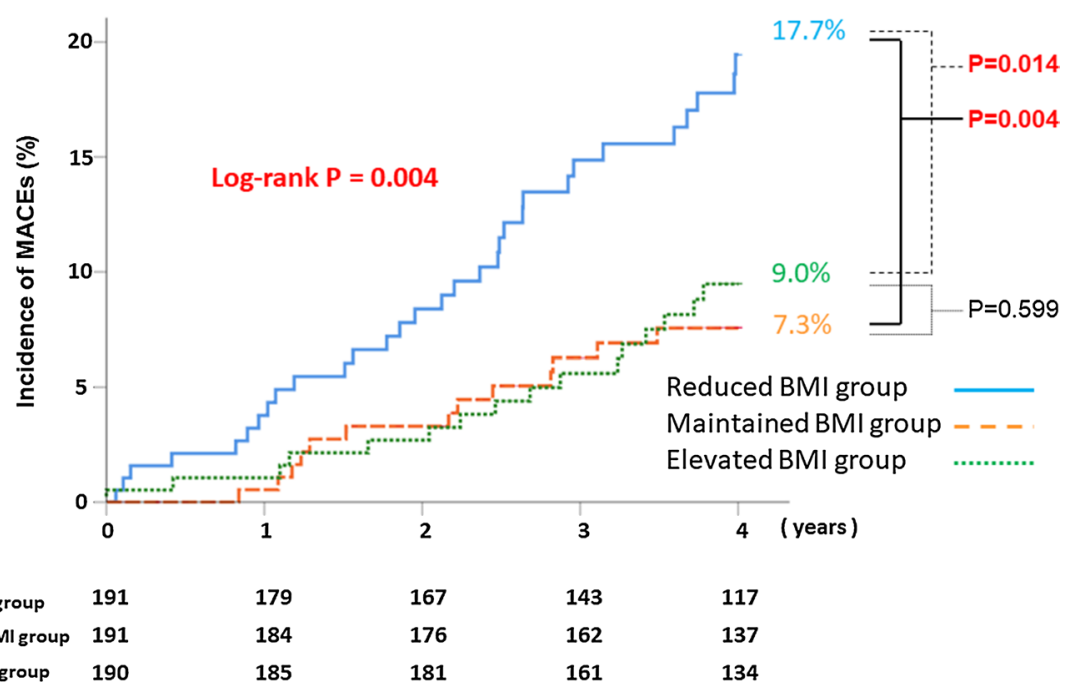


Fig. 3 Kaplan-Meier analysis for the incidences of all-cause death, cardiac death, QMI, stroke. Kaplan-Meier curves are shown for the cumulative incidence of all-cause mortality, cardiac death, myocardial infarction, and stroke. The reduced BMI group $\left(<-0.52 \mathrm{~kg} / \mathrm{m}^{2} ; n=191\right)$ has a significantly higher incidence of all-cause mortality, cardiac death, and myocardial infarction than the maintained BMI group $\left(-0.52\right.$ to $\left.0.38 \mathrm{~kg} / \mathrm{m}^{2} ; n=191\right)$ and elevated BMI group $\left(\geq 0.38 \mathrm{~kg} / \mathrm{m}^{2} ; n=190\right)$. BMI body mass index, $Q M I$ Q-wave myocardial infarction

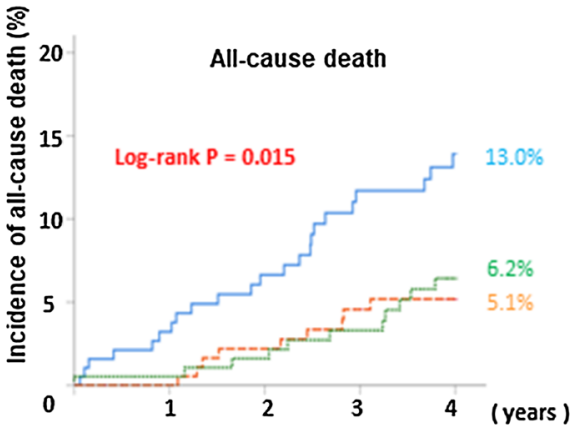

Reduced BMI group Maintained BMI group - - Elevated BMI group
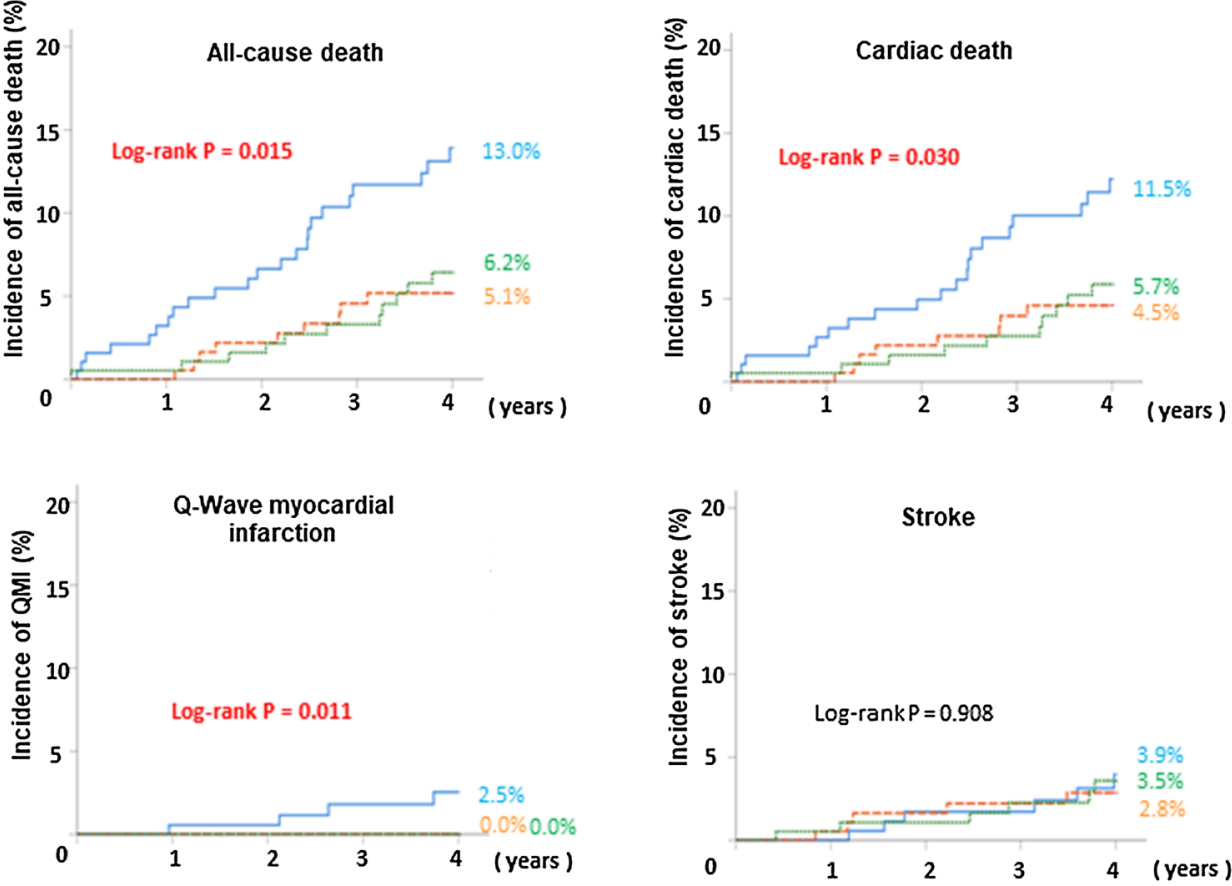

Table 3 Univariate and multivariable predictors of major adverse cardiac or cerebrovascular events

\begin{tabular}{llrlr}
\hline Variable & Unadjusted HR $(95 \%$ CI $)$ & $p$ value & Adjusted HR (95\% CI) & $p$ value \\
\hline Age & $1.069(1.037-1.101)$ & $<0.001$ & $1.056(1.025-1.087)$ & $<0.001$ \\
Sex & $1.323(0.688-2.545)$ & 0.401 & & \\
LVD & $1.002(0.431-2.332)$ & 0.996 & & \\
HT & $1.206(0.653-2.229)$ & 0.550 & & 0.022 \\
DLp & $0.456(0.274-0.761)$ & 0.003 & $0.547(0.326-0.917)$ & \\
DM & $1.352(0.812-2.254)$ & 0.246 & & \\
Smoking & $0.973(0.579-1.636)$ & 0.973 & & \\
Af & $1.354(0.616-2.979)$ & 0.451 & & 0.014 \\
ACS & $1.278(0.770-2.120)$ & 0.342 & & 0.003 \\
High BMI & $0.667(0.167-2.732)$ & 0.574 & & \\
Low BMI & $3.017(1.371-6.640)$ & 0.006 & $2.768(1.233-6.213)$ & \\
Reduced BMI & $2.231(1.345-3.703)$ & 0.002 & $2.244(1.342-3.755)$ & \\
\hline
\end{tabular}

$A C S$ acute coronary syndrome, $A f$ atrial fibrillation, $D M$ diabetes mellitus, DLp dyslipidemia, High BMI high body mass index $\left(>30 \mathrm{~kg} / \mathrm{m}^{2}\right)$ immediately after percutaneous coronary intervention, $H T$ hypertension, Low $B M I$ low body mass index $\left(<18.5 \mathrm{~kg} / \mathrm{m}^{2}\right)$ immediately after percutaneous coronary intervention, $L V D$ left ventricular dysfunction (left ventricular ejection fraction $\leq 40 \%$ ), reduced $B M I$ reduced body mass index $\left(<-0.52 \mathrm{~kg} / \mathrm{m}^{2}\right), C I$ confidence interval, $H R$ hazard ratio treatment. The original mean BMI was normal in each group, and there was no significant difference among groups. The BMI after the 1-year follow-up was also in the normal range in each group.

Although it is unknown in the present study whether patients intentionally lost weight, some studies reported that observational weight loss is associated with increased adverse cardiovascular events, whereas intentional weight loss is associated with decreased clinical events [13]. It is necessary to pay attention to unexpected weight loss in patients with CAD after PCI.

Several reasons for the worsening of prognosis due to weight loss have been reported. One of the causes of poor prognosis due to low body weight is the rapid progression of cachexia. In cachectic patients, skeletal muscle and adipose tissue are reduced $[14,15]$. Skeletal muscle loss increases 
the risk of adverse outcomes, including physical disability, poor quality of life, and death [16]. A study reported that myonectin secreted from skeletal muscle suppresses apoptosis and inflammation in the heart, suggesting that myonectin mediates some of the beneficial actions of the cardiovascular system [17]. In adipose tissue, adiponectin suppresses arteriosclerosis and improves insulin resistance [18]. Thin patients with heart disease have high tumor necrosis factor (TNF) $\alpha$ levels [19]. TNF $\alpha$ is an indicator of systemic inflammation and a poor prognostic factor in patients with heart disease $[19,20]$. Obese people have low peripheral vascular resistance, whereas thin people have high vascular resistance. Systemic vascular resistance is associated with the severity of cardiovascular disease [21]. Although it is not clear why weight loss after PCI affected poor prognosis in this study, these acute physical stresses due to short-term weight loss are thought to exacerbate the prognosis after PCI.

The patients in the present study were mainly elderly people $(70.2 \pm 10.3$ years), and aging diseases can cause weight loss. It has been pointed out that aging itself leads to a decrease in immune response and that thin elderly people may be less resistant to infection [22]. Reduced immunity due to weight loss is thought to affect total death.

Obesity is often evaluated using BMI, which is the simplest tool. However, BMI cannot measure fat and muscle mass, nor can it measure visceral fat. Patients with more fat and less muscle mass have a worse prognosis after PCI [23]. Further, the higher the proportion of visceral fat, the higher the risk of CAD [24]. However, it is difficult to measure muscle mass and visceral fat mass in terms of burdens, such as time and cost, in routine examinations. In that respect, BMI can be easily measured in any situation.

In this study, physical activity and cardiorespiratory fitness (CRF) are not evaluated. Some studies show that sustained physical activity and CRF are associated with substantial mortality risk reduction than BMI. Individuals with CAD are recommended to be physically active [25] and to improve their CRF [26, 27]. Furthermore, changes in physical activity had lower all-cause mortality risk than changes in BMI [28]. However, a comparison of changes in physical activity is sometimes difficult to evaluate by an interview, and the measurement of CRF is also difficult in terms of costs than BMI.

In the heart failure era, obesity is a risk factor of developing heart failure; however, obesity works to prevent exacerbation of heart failure in patients who are being treated for chronic heart failure after onset, and low weight is a risk factor for exacerbation of heart failure, i.e., the obesity paradox [25]. Even in the ischemic region, the approach to weight management before and after PCI may change. Although high BMI is a risk factor of developing ischemic events, this study suggests that weight gain after PCI is not a poor prognostic factor, and weight loss after PCI may be a poor prognostic factor. On the other hand, compared to the maintained BMI group, elevated BMI group also shows a little worse outcome, even not statistically significant. In the future, it will be necessary to conduct a positive study with a bigger number of data on the effect of weight change after PCI on prognosis.

\section{Limitations}

This study has several limitations. First, there is possible observer bias because this study was designed as an investigator-driven observational study. Second, in this study, we did not know whether the weight loss was intentional. Third, because the bodyweight cannot be measured after PCI, the sample size was small. Fourth, external monitoring of this registry was lacking. Lastly, there is no consensus on the follow-up of weight changes and outcomes and needs to be considered.

\section{Conclusions}

The long-term clinical outcomes of patients with CAD who underwent PCI were affected by the reduction in BMI after PCI. Furthermore, elevation of BMI after PCI was not a poor prognostic factor. The current study demonstrated that stratification using a change in BMI after PCI may help to predict adverse events in patients with CAD. Long-term studies in larger populations are needed to assess the clinical validation of changes in BMI after PCI with regard to long-term outcomes and in the general population.

Acknowledgments We would like to thank all cardiologists and medical technologists who were involved in the acquisition of data.

Funding This research did not receive any specific grant from funding agencies in the public, commercial, or not-for-profit sectors.

\section{Compliance with ethical standards}

Conflict of interest The author declares that they have no conflict of interest.

Open Access This article is licensed under a Creative Commons Attribution 4.0 International License, which permits use, sharing, adaptation, distribution and reproduction in any medium or format, as long as you give appropriate credit to the original author(s) and the source, provide a link to the Creative Commons licence, and indicate if changes were made. The images or other third party material in this article are included in the article's Creative Commons licence, unless indicated otherwise in a credit line to the material. If material is not included in the article's Creative Commons licence and your intended use is not permitted by statutory regulation or exceeds the permitted use, you will need to obtain permission directly from the copyright holder. To view a copy of this licence, visit http://creativecommons.org/licenses/by/4.0/. 


\section{References}

1. Adams KF, Schatzkin A, Harris TB, Kipnis V, Mouw T, BallardBarbash R, Hollenbeck A, Leitzmann MF (2006) Overweight, obesity, and mortality in a large prospective cohort of persons 50 to 71 years old. N Engl J Med 355:763-778

2. Tsugane S, Sasaki S, Tsubono Y (2002) Under- and overweight impact on mortality among middle-aged Japanese men and women: a 10-y follow-up of JPHC study cohort I. Int J Obes Relat Metab Disord 26:529-537

3. Flegal KM, Graubard BI, Williamson DF, Gail MH (2005) Excess deaths associated with underweight, overweight, and obesity. JAMA 293:1861-1867

4. Kenchaiah S, Evans JC, Levy D, Wilson PW, Benjamin EJ, Larson MG, Kannel WB, Vasan RS (2002) Obesity and the risk of heart failure. N Engl J Med 347:305-313

5. Anker SD, Ponikowski P, Varney S, Chua TP, Clark AL, WebbPeploe KM, Harrington D, Kox WJ, Poole-Wilson PA, Coats AJ (1997) Wasting as independent risk factor for mortality in chronic heart failure. Lancet 349:1050-1053

6. Kenchaiah S, Pocock SJ, Wang D, Finn PV, Zornoff LA, Skali H, Pfeffer MA, Yusuf S, Swedberg K, Michelson EL, Granger CB, McMurray JJ, Solomon SD, Investigators CHARM (2007) Body mass index and prognosis in patients with chronic heart failure: insights from the Candesartan in Heart failure: assessment of reduction in mortality and morbidity (CHARM) program. Circulation 116:627-636

7. Fonarow GC, Srikanthan P, Costanzo MR, Cintron GB, Lopatin M, ADHERE Scientific Advisory Committee, and Investigators (2007) An obesity paradox in acute heart failure: analysis of body mass index and inhospital mortality for 108,927 patients in the Acute Decompensated Heart Failure National Registry. Am Heart J 153:74-81

8. Lavie CJ, Milani RV (2003) Obesity and cardiovascular disease: the hippocrates paradox? J Am Coll Cardiol 42:677-679

9. Lavie CJ, Milani RV, Ventura HO (2007) Obesity, heart disease, and favorable prognosis-truth or paradox? Am J Med 120:825-826

10. Lavie CJ, Milani RV, Ventura HO (2008) Untangling the heavy cardiovascular burden of obesity. Nat Clin Pract Cardiovasc Med 5:428-429

11. Romero-Corral A, Montori VM, Somers VK, Korinek J, Thomas RJ, Allison TG, Mookadam F, Lopez-Jimenez F (2006) Association of bodyweight with total mortality and with cardiovascular events in coronary artery disease: a systematic review of cohort studies. Lancet 368:666-678

12. Ndrepepa G, Fusaro M, Cassese S, Guerra E, Schunkert H, Kastrati A (2015) Relation of body mass index to bleeding during percutaneous coronary interventions. Am J Cardiol 115:434-440

13. Pack QR, Rodriguez-Escudero JP, Thomas RJ, Ades PA, West CP, Somers VK, Lopez-Jimenez F (2014) The prognostic importance of weight loss in coronary artery disease: a systematic review and meta-analysis. Mayo Clin Proc 89:1368-1377

14. Florea VG, Moon J, Pennell DJ, Doehner W, Coats AJ, Anker SD (2004) Wasting of the left ventricle in patients with cardiac cachexia: a cardiovascular magnetic resonance study. Int J Cardiol 97:15-20

15. Florea VG, Henein MY, Rauchhaus M, Koloczek V, Sharma R, Doehner W, Poole-Wilson PA, Coats AJ, Anker SD (2002) The cardiac component of cardiac cachexia. Am Heart J 144:45-50

16. Cruz-Jentoft AJ, Baeyens JP, Bauer JM, Boirie Y, Cederholm T, Landi F, Martin FC, Michel JP, Rolland Y, Schneider SM,
Topinková E, Vandewoude M, Zamboni M (2010) European Working Group on Sarcopenia in Older People. Sarcopenia: European consensus on definition and diagnosis: Report of the European Working Group on Sarcopenia in Older People. Age Ageing 39:412-423

17. Otaka N, Shibata R, Ohashi K, Uemura Y, Kambara T, Enomoto T, Ogawa H, Ito M, Kawanishi H, Maruyama S, Joki Y, Fujikawa Y, Narita S, Unno K, Kawamoto Y, Murate T, Murohara T, Ouchi N (2018) Myonectin is an exercise-induced myokine that protects the heart from ischemia-reperfusion injury. Circ Res 123:1326-1338

18. Rauchhaus M, Clark AL, Doehner W, Davos C, Bolger A, Sharma R, Coats AJ, Anker SD (2003) The relationship between cholesterol and survival in patients with chronic heart failure. J Am Coll Cardiol 42:1933-1940

19. Levine B, Kalman J, Mayer L, Fillit HM, Packer M (1990) Elevated circulating levels of tumor necrosis factor in severe chronic heart failure. N Engl J Med 323:236-241

20. Rauchhaus M, Doehner W, Francis DP, Davos C, Kemp M, Liebenthal C, Niebauer J, Hooper J, Volk HD, Coats AJ, Anker SD (2000) Plasma cytokine parameters and mortality in patients with chronic heart failure. Circulation 102:3060-3067

21. Uretsky S, Messerli FH, Bangalore S, Champion A, CooperDehoff RM, Zhou Q, Pepine CJ (2007) Obesity paradox in patients with hypertension and coronary artery disease. Am J Med 120:863-870

22. Chandra RK (1997) Nutrition and the immune system: an introduction. Am J Clin Nutr 66:460s-463s

23. Romero-Corral A, Somers VK, Sierra-Johnson J, Korenfeld Y, Boarin S, Korinek J, Jensen MD, Parati G, Lopez-Jimenez F (2010) Normal weight obesity: a risk factor for cardiometabolic dysregulation and cardiovascular mortality. Eur Heart J 31:737-746

24. Tanaka T, Kishi S, Ninomiya K, Tomii D, Koseki K, Sato Y, Okuno T, Sato K, Koike H, Yahagi K, Komiyama K, Aoki J, Tanabe K (2019) Impact of abdominal fat distribution, visceral fat, and subcutaneous fat on coronary plaque scores assessed by 320row computed tomography coronary angiography. Atherosclerosis 287:155-161

25. Moholdt T, Lavie CJ, Nauman J (2017) Interaction of physical activity and body mass index on mortality in coronary heart disease: data from the Nord-Trøndelag Health Study. Am J Med 130:949-957

26. Barry VW, Caputo JL, Kang M (2018) The joint association of fitness and fatness on cardiovascular disease mortality: a metaanalysis. Prog Cardiovasc Dis 61:136-141

27. Elagizi A, Kachur S, Lavie CJ, Carbone S, Pandey A, Ortega FB, Milani RV (2018) An overview and update on obesity and the obesity paradox in cardiovascular diseases. Prog Cardiovasc Dis 61:142-150

28. Moholdt T, Lavie CJ, Nauman J (2018) Sustained physical activity, not weight loss, associated with improved survival in coronary heart disease. J Am Coll Cardiol 71:1094-1101

29. Lavie CJ, Milani RV, Ventura HO (2009) Obesity and cardiovascular disease: risk factor, paradox, and impact of weight loss. J Am Coll Cardiol 53:1925-1932

Publisher's Note Springer Nature remains neutral with regard to jurisdictional claims in published maps and institutional affiliations. 